\title{
Investigation and Comparison of Time and Location of Contract Conclusion in Iranian Electronic Commerce Act and UNCITRAL Model Law
}

\author{
Seyed Abolhasan Mosavi ${ }^{1}$ \& Abdolmohammad Afrogh ${ }^{2}$ \\ ${ }^{1}$ Department of Criminal Law, Criminal Law Student Faculty, Boushehr Branch, Islamic Azad University, \\ Boushehr, Iran \\ ${ }^{2}$ Department of Criminal Law, Public International Law Faculty, Dashtestan Branch, Member Islamic Azad \\ University, Dashtestan, Iran \\ Correspondence: Abdolmohammad Afrogh, Department of Criminal Law, Public International Law Faculty, \\ Dashtestan Branch, Member Islamic Azad University, Dashtestan, Iran. E-mail: mouhamad_afrogh@yahoo.com
}

Received: September 4, 2016 Accepted: October 2, $2016 \quad$ Online Published: December 29, 2016

doi:10.5539/jpl.v10n1p145 URL: http://dx.doi.org/10.5539/jpl.v10n1p145

\begin{abstract}
Cyberspace is considered as one of the most modern means for the conclusion of contracts and meeting the obligations arising from that, particularly in commercial transactions. The nature of electronic contracts- in terms of credibility, form and homogeneity with public disciplines and regulations of civil law about the contracts- is a new topic based on which recognition and investigation on the legal effects depend on the formal structure of cyberspace and information and communication technology concepts known in this area. Present work mainly investigates following items: Electronic contract conclusion and specific properties of such agreements, effect of electronic trait on its way of formation as well as compatibility of public rules and regulation of electronic contracts in Iranian Electronic Commerce Acts and UNCITRAL model law. Electronic contract principally does not differ traditional ones in terms of nature. However, structure of cyberspace has brought up new specifications and concepts. A descriptive-analytical method with comparative approach were used for data collection. Current rules and regulations of the contracts area in traditional space seem to not be able to completely meet emerging rights in cyberspace, but beside traditional legal basics, some rules and regulations are necessary to eliminate existing confusion by setting determination in modern legal uncertainties. Present study tries to answer above queries by assessment and comparison of the location and time of contract conclusion in Electronic Commerce Act and UNCITRAL Model Law.
\end{abstract}

Keywords: electronic commerce, place and time of contract conclusion, UNCITRAL Model Law, data message, electronic signature

\section{Research History}

Given the conducted studies on subject of the present proposal entitled "Investigation and Comparison of time and location of contract conclusion in Iranian Electronic Commerce Acts and UNCITRAL Model Law" in published books and papers, this result was found that the title of mentioned study has experience in nor domestic field neither international one while it was not analyzed analytically, as well. However, there are some experiences with low similarity in form and nature which are mentioned as follows:

\subsection{Rashidi (2011), Electronic or Traditional Commerce?}

The author believes a fundamental difference between E-commerce and traditional trade in the way of information exchange. In the latter, the information was transferred through face-to-face communication or at most by phone or postal system, while in the former, this process is carried out by computer networks. This difference has caused such problems as insecurity, customers' distrust, and disclosure of people's identity in internet for each of which there are few solutions but some specific equipment is required for implementation.

\subsection{Vesali Naseh (2007), Electronic Contract and the Foundations of Its Credibility}

The author of this paper addresses that one of the most important legal issues of e-commerce is a conclusion of binding contracts. Information technology has allowed lots of business transactions and service delivery to be 
done through internet. Expansion of this kind of trade and commercial relations among individuals has been along with addressing some legal issues on rules governing on people's contractual relations. These are some important topics in this area: recognition of modern communication technologies in contract formation, the way of their formation and credibility, the ability to assign electronic documents, issues related to electronic signatures, the way of electronic payments, etc.

\subsection{Feizi Chekab (2004), the Time of Contract Conclusion through Electronic Intermediaries (Electronic Commerce Law's Alignment with the Rules Governing the Trade), Public Law Research Journal, Issue 13}

The author here believes that since the electronic contracts' parties are often in a separate place and the contract is concluded remotely, the exchanged offer and acceptance between the seller and the buyer may not have the symmetry and time sequence. This situation makes at least two questions. When is the contract conclusion? Where is the contract conclusion? The answers have a fundamental impact on the fate and effects of contract and may revolutionize the parties' rights and assignments because credibility or nullity of the contract, the court governing the contract, the law governing the contract, starting obligations of the parties, the warranty period and even contract and so on entirely depend on time and location of contract conclusion.

\subsection{Hasani (2007), Requirements and Needs for E-Commerce in Iran, Iranian Industry Innovators Website}

The author in this paper introduces the concept of e-commerce and the corresponding requirements and needs of setting up e-commerce as well as obstacles and problems in Iran. Also, he addresses that such terms as electronic city, electronic government, electronic citizenship and so on are arising from the increasing significance of communication technologies in daily life. E-Commerce is one of the actions promoted by modern communication technologies.

Many economists and experts believe that a revolution similar to the industrial revolution has taken place that made the world into the information area and has substantially revolutionized plenty of economic, social and cultural aspects of the human life. The increasing growth of technology in the world, particularly Information Technology (IT) has decreased temporal and spatial barriers to trade and public internet access allows conducting the business through internet or in other words, e-commerce and electronic business have found a special position in developed countries. In recent years, with the gradual abandonment of traditional paper-based commerce and the physical exchange of documents, e-commerce has been prevailing.

\section{Importance and Necessity of Research}

E-commerce is known as a pioneer in IT domain and plays an important role both theoretically and practically in domestic and international business society. The importance of e-commerce, technical and legal obstacles to its development, as well as the efforts of the Islamic Republic of Iran in the mirror of government decisions require to assess obstacles and corresponding technical and legal solutions.

Since one of the most important legal topics of e-commerce is electronic contracts, IT allows to conducts lots of business transactions and service delivery through the internet. The expansion of such kind of trade and commercial relationships among individuals has been along with addressing some legal issues on rules governing on people's contractual relationships. These are some important topics in this area: recognition of modern communication technologies in contract formation, the way of their formation and credibility, the ability to assign electronic documents, issues related to electronic signatures, the way of electronic payments, etc. As a comparative work, this study tries to present a suitable solution for resolving existing problems in e-commerce, clarifying these issues. According to an increasing expansion of information technology and the internet and thereby contract's conclusion through this network, we would better to assess the time and location of contract conclusion in e-commerce more precisely, specify silence of the law items and find a solution for that. Also, we should create an operational environment of e-commerce along with corresponding software with the expansion ability and promotion of e-commerce culture.

\subsection{Research Questions}

1) Are time and location of contract conclusion in e-commerce law compatible with those of UNCITRAL rules?

2) In case the person has no specific residence, what provisions have been considered by e-commerce law and UNCITRAL rules about location of contract conclusion?

3) If the data message is entered incomprehensibly into the information system, is the receipt achieved and does it make an obligation?

4) How can the basic conditions be obtained for a valid electronic contract conclusion? 


\subsection{Research Hypotheses}

1) E-commerce Act and UNCITRAL model law have some differences and similarities in terms of time and location of contract conclusion.

2) In e-commerce platform, from the four theories, receipt theory is accepted.

3) If the data message is entered incomprehensibly into the information system of audience, the receipt is achieved and it makes an obligation.

\subsection{Methodology}

The present study was conducted in the descriptive-analytical method. In the present work, library method was used such that by referring authoritative scientific and specialized libraries, the research can proceed better and the internet was also used in order to be coordinated with updated content. Taking notes were used as the required tools for data collection.

\subsection{Scope}

Identification, assessment and comparison on the time and location of contract in the e-commerce Act and UNCITRAL model law and evaluation of these basics of various aspects by analytical and descriptive method and if possible, finding the right solution to solve the common problems in the contract and e-commerce.

\section{Theoretical Concepts}

\subsection{What Is E-Commerce?}

Diverse definitions have been provided for e-commerce few of which are pointed here:

- All aspects and processes of the market which can be done by internet and web technology are called e-commerce. (Zargar, Strategic models and business solutions in internet, 2001).

- Generally, the term "e-commerce" refers to the electronic transactions which are done through communication networks. Initially, buyer or consumer looks for a virtual/online shop through the internet and orders the goods by means of web or e-mail. Finally, he will receive the goods (Nikbakhsh Tehrani and Saberi, Awareness with e-commerce and its infrastructures, 2001).

- E-commerce means running business transactions in electronic format. (Sanayeei, e-commerce in the third millennium, 2002).

- Application of Information Technology in Trade (Ahmadi and M. Virginiari, e-commerce, 2002).

- E-commerce means electronic exchange of data. In a nutshell, data electronic exchange includes generation, process, application and exchange of information and documents in electronic and automatic methods between computer systems and based on common language and specific standards with the least human contribution. However, e-commerce includes an area much wider than electronic exchange that is a revolution in communication field. As the simplest definition, e-commerce means finding resources, conducting an evaluation, negotiating, ordering, delivery, payment and support services which are done electronically. Therefore, e-commerce is a method based on which information, products and services are purchased and sold through computer communication networks (Alipour Hafezi, e-commerce in information centers, 2001).

- E-commerce points all business activities which are carried out using computer communication networks, particularly internet. E-commerce is somehow a paperless trade. By e-commerce, buy-and-sale information exchange as well as goods transportation data will be done effortlessly with higher acceleration of banking transactions. To be communicated with each other, the companies will not have current constraints and their communication will be done simpler and quicker. The communication of sellers and buyers can be customer-by-customer in very low expense (Ghezel Ayagh, Internet based e-commerce, 2001).

- E-commerce method is known as paperless trade which brings up time, cost and human resources saving and improves productivity indicators, while it has not found its real position in Iran. In this paper, in addition to providing a definition of e-commerce concept, its advantages in global trade and business and commercial transactions will be explained. Furthermore, the reasons for lack of spread of this phenomenon in Iran and development strategies and progress in this area will be presented (Bagheri and Hassan, 2012b).

\subsection{The Way of Electronic Contracts Conclusion and the Corresponding Features}

The cyberspace internet is considered as one of the most modern means for contracts conclusion and fulfillments of the arisen commitments particularly in the business transactions area. The nature of electronic contracts- in terms of credibility, form and homogeneity with public disciplines and regulations of civil law about the 
contracts- is a new topic that recognition and investigation on the legal effects depend on the formal structure of cyberspace and information and communication technology concepts known in this area. Present work mainly investigates following items: Electronic contract conclusion and specific properties of such agreements, effect of electronic trait on its way of formation as well as compatibility of public rules and regulation of electronic contracts in Iranian laws and UNCITRAL rules. Electronic contracts generally do not differ traditional ones in terms of nature. However, the new structure of cyberspace has provided new features and concepts for such contracts. In doing so, formal structure and technical specification of cyberspace can be argued to result in modern and wide revolution in diverse aspects of the law of contracts which potentially will affect concepts of contracts conclusion.

\subsection{Electronic Contracts}

In terms of the basic conditions of the contract and its corresponding effects, the electronic contract follows general provisions and rules of contract law and obligations. However, in terms of technical specifications and conclusion methods as well as the way of legal effects support, the electronic contract requires recognition and strict compliance with the principles and general rules governing the contract. In terms of the accuracy or topic, the electronic contracts actually do not have a different nature compared to conventional contracts. However, they are considered as a new description on the contract's conclusion that for their adjustment no specific regulations were predicted by the legislator. Some lawyers define electronic contract as follows: Electronic contract is an agreement that the parties' acceptance and offer are exchanged by the open international telecommunications network as well as means of audio and video (Abu Al Hasan Mujahid, Osame 2000, P39).

This definition only addresses the general way of offer and acceptance intersection and has said nothing about the effects on offer and acceptance exchange. Other lawyers have defined electronic contract as follows: it is a contract where the offer and acceptance are concluded using an international communication network in order to make contractual obligations through electronic data exchange (Mamduh Ibrahim, Khalid, 2005, p51).

\subsection{The Difference of Electronic Data Exchange and E-Commerce}

In many cases, electronic data exchange is considered as a synonym for e-commerce and each is used instead of another. These two technologies are not the same at all and are quite different. However, e-commerce can be argued as a supplementary for electronic exchange.

Electronic data exchange is defined as a mechanism through which data transfer and exchange are done to achieve the business activities with defined structure and form and utilizing international standardized messages by electronic means. Nevertheless, e-commerce is paperless transaction where the electronic data exchange is used as a tool along with e-mail, electronic bulletin boards, electronic transmission, or other network-based technologies. In other words, electronic data exchange serves as the backbone of e-commerce. As it can be seen from the above definition, e-commerce encompasses a much wider area than electronic data exchange (Mirabi and Sarvsaeidi, 2003).

E-commerce method is known as paperless trade, which brings up the saving time, cost and human resources and improves productivity indicators, while it has not found its real position in Iran. In this paper, in addition to providing a definition of e-commerce concept, its advantages in global trade and business and commercial transactions will be explained. Furthermore, the reasons for lack of spread of this phenomenon in Iran and development strategies and progress in this area will be presented.

\subsection{Determining Time and Place of Electronic Contracts Conclusion}

Regarding determination of contract time in contemporary legal systems, four main solutions are known as follows: since the declaration of acceptance, time to send acceptance, the time of receipt of the acceptance and awareness time of offeror. In Iranian civil law at provisions of Article 191 "contracts can be fulfilled with the intention of being written provided on being affordable on what implies that intention", are more compatible with wide concept of acceptance declaration (Ghasemzadeh, 2006, p68).

However, some of authors in the civil law field often know acceptance transmission in logical and practical aspect, by approving foundations of the acceptance declaration theory (Safaei, 2007, p76; Shahidi, 1998, p164).

Therefore, according to civil law, contracts conclusion time is when the audience accepts offer provisions. However, this solution is not implicitly common in commercial transactions and contract conclusion time often follows sending time or acceptance receipt by the offeror. Although electronic contract's conclusion time validity depends on general rules governing the contract in civil law and common law procedures. However, according to electronic communication methods and specific regulations that the legislator has explicitly predicted in e-commerce law, electronic contract's conclusion time is considered at the electronic acceptance 
acknowledgment. Electronic Commerce Act (1993) expressly does not refer to the contract conclusion time. Nevertheless, given the Electronic Commerce Act, the data message transmission validity is provided on the entrance of this data into an information system out of control originator or his deputy. In terms of validity and referablity to data message, it should be noted that the Electronic Commerce Act considers the data message as a written as it is pointed in Article 6 .

\subsection{The Time of Contract Formation}

As mentioned earlier, the contract is concluded when a valid acceptance is attached to offer. Now, the question is that in terms of contract conclusion time, when is an acceptance valid achieved from? In the past when the contract parties or their agents were present in a location, offer and acceptance were done on the spot and thereby determination of time and place of acceptance and thus time and place of contract conclusion were not difficult. Even now, if the parties are present in a place, it will be still easy to determine time and place of contract formation. But in case the acceptance is declared through post, fax, telex or modern electronic communication tools (e.g. e-mail or chat room), the acceptance time and place and thereby contract formation will be difficult and controversial. For example, in an acceptance declaration through letter, is acceptance time valid while writing and signing or sending time for offeror? Or, when it is received by him or even when the letter is read by him, does he get aware of the content? In doing so, within the contract formation through websites or chat rooms, when and where is the time and place of contract formation?

In order to answer these questions, four different theories are presented. Someone suffices "acceptance declaration" for contract formation and someone applies "sending theory". In addition, some other one considers the time of "acceptance reception" by offeror as the acceptance time and thereby contract conclusion time and someone else has gone beyond and believe in "information theory" and consider acceptance from the time that offeror is informed of acceptance provisions. Among the mentioned theories, the two ones "sending" and "reception" have been more popular in legal systems (Habibzadeh, 2011).

\section{Location to send and receive data messages and electronic communications}

In electronic contract's conclusion where it is possible to do offer and acceptance through a data message and electronic communication, the location of sending and receiving data message and electronic communication will be effective on contract conclusion place determination.

\subsection{Location to Send Data Message and Electronic Communication}

In order to determine data sending place, E-commerce model law has considered the parties' business place as the criterion not location of information systems. The parties usually do not know location of information systems through which the communication is made and even it may be changed. Therefore, it will be very difficult to determine location of information systems as the location of sending message. In addition, when the location of message sending is criterion in such important cases as conflict of laws, it will be reasonable to relate sending location to sender and receiver themselves not to the location of parties' information system. Hence, the model law states that except the cases where another way is agreed between sender and receiver, the data message sending place is assumed as the place where sender's business is located. If the parties agree on location of sending data message, the agreed location will be considered as the standard and there will be no doubt on this agreement. Otherwise, the business place of originator- someone generating and sending data message- will be the standard. In case the originator has more than one business place (multi-location), the business place is somewhere with the closest relation to the transaction between the parties. The phrase "transaction between parties" refers to both real carried out transactions and the transactions which are going to be done by the parties. In case with no transaction between the parties, the main location will be the standard. However, in an assumption the parties may have no business location, in this case, the common residence will be the standard (Ibid).

\subsection{The Place to Receive Data Message and Electronic Communication}

As what mentioned for the place of sending a data message, e-commerce act has chosen the business place as the standard for data reception place because the information system which receives data or the system which is used by receiver for data message recovery may be located in a jurisdiction other than receiver's residence. In order to find a reasonable relation between the receiver and place of data message reception and the simplicity to be determined by the originator, the model law has chosen the business place as the standard and states that "the data message reception place is receiver's business location". Accordingly, the parties' agreement in this regard is precedence over legal regulation, as per sending location. Otherwise, if the receiver has more than one business place, the business place will be somewhere with the closest relation with the main deal. 
If there is no transaction, the main business place will be the standard. Accordingly, in case of lack of business place, the ordinary residence will be considered as a data message reception place. What implied from this regulation is that a difference is considered between assumed place of data message reception and the real place where data message is reached at the time mentioned in section 2 of article 15 . However, this distinction is meant only through the computer so that plenty of interfaces can be imagined between message sending and reception time. This assumption cannot be applied regarding telex and telegram (Ibid).

\subsection{The Basic Conditions of Contracting in Electronic Contracts}

It is now for more than forty years, use of modern communication technologies (as a prime example Internet), communications have been revolutionized and have had significant impacts on all aspects of individual and social of human life. Following the modern communications, a new world is made that has emerged across the real world. The world where geographical borders are no more meaningful and traffic needs nor passport neither visa and it is feasible for everybody even without entity. The communication is done in a very high speed that they seem to be set up in the alleys of a small village. The individuals who have suitably taken advantage of this possibility are pioneers in their activity, whether in media, training and culture promotion (with positive and negative goals) or in modern business world. Present study considers some legal issues of the business world in cyberspace among which the principles governing electronic contracts formation is one of those issues. It can be concluded that electronic contracts and their principles (e.g. how, where and when these contracts are formed) are important not only in academic and theoretical issues but also in business and practical aspects (Ibid).

\subsection{Capacity of Electronic Contracts' Parties in UNCITRAL Model Law and Iranian Electronic Commerce Act}

\subsubsection{Transaction Party}

Fundamentally, presence of at least two parties is necessary for the formation of a contract. In electronic contract's conclusion, the transactions typically are performed through electronic means while in some contracting methods, human resources have no direct contribution and the computer acts automatically on behalf of them. Therefore, regardless of the formalities for electronic transactions, volition is assumed to be existing in each part of the transaction. One of the most important difficulties of electronic contract's conclusion is the lack of the necessary environment for customary awareness of each party of each other's capacity and real character for contracting. In this case, each party should be satisfied of presented information and plaintiff will be in charge of invalidity proof of electronic contract due to a party's incapacity. As mentioned earlier, data message which assures volition looks like other arguable evidences in a lawsuit and its invalidity can be proved due to other evidences, as well. According to Article 12 of the E-commerce Act, evidences and reasons for substantiation of claims may be data message and with no trial or governmental office, probative value (data message) of each fundamental element for contract validity cannot be rejected based on existing evidence rules only due to form and format.

As per E-commerce Act, the existence of originator, receiver and data message exchange are necessary for conclusion of legal relationship in cyberspace. However, in accordance with paragraph (b) and (c) of Article 2 of the Electronic Commerce Act, these parties do not mean a person who acts as an interface in relation to the message data. In terms of data message and in addition to this Act, the legislator has divided related items to originator into two cases. Otherwise, data message will not be related to the originator. In accordance with Article 18 of mentioned Act, the data message cases related to the originator include: A. If it is sent by the originator or someone authorized by him; B. if sent by planned information system or automatic charge through the originator. Therefore, in electronic contracts where contacts are concluded automatically, the computer serves as a means under control and volition of the parties.

\subsection{Electronic Contract and Its Validity in UNCITRAL Model Law and Electronic Commerce Act}

One of the most important legal issues of e-commerce is a conclusion of binding contracts. Information Technology has allowed lots of transactions and services to be done through internet. Expansion of this kind of trade and commercial relations among individuals has been along with addressing some legal issues on rules governing on people's contractual relations. These are some important topics in this area: recognition of modern communication technologies in contracts formation, the way of their formation and credibility, the ability to assign electronic documents, issues related to electronic signatures, the way of electronic payments, etc. The mentioned issues are addressed due to special specifications of electronic contracts conclusion environment and even in many cases, no new legislation is required, but by analysis and assessment of existing rules, the appropriate response can be found for addressed challenges of contracts law in cyberspace and also as possible new legislation can be prevented. What mentioned does not mean that the new environment of electronic transactions do not need new legislation. It should be accepted that internet (as the location of individuals' legal 
relations) has some specifications which were absent in the technologies prior to internet emergence. For this reason, the made revolutions and changes in individuals' legal and transaction relations are paid into attention by legal systems and most of them have applied for providing a legal framework and legislative structuring in order to enact a new law or modify existing laws.

In Iran, in order to recognize new communication facilities in trade or in better words, national and international transactions, a law called "Electronic Commerce Act" has been adopted in which the concluded contracts are recognized through electronic interfaces, electronic documents and evidences and electronic signature and some legal aspects addressed in the electronic commerce field are paid into attention. This Act, which is a translation from UNCITRAL e-commerce model law, is actually considered as a legal base for e-commerce in Iran and is granted a legal prestige to individuals' trade relationships in the internet. However, general terms of general contracts are still valid in electronic ones and in cases of silence or ambiguity of the Electronic Commerce Act, they can be referred.

\subsection{Remote Contracting in UNCITRAL Model Law and Iranian Electronic Commerce Act}

It's important to determine contract formation time in order to identify parties' rights and assignments since as long as the contract has not been concluded, the offeror can withdraw his offer. However, upon the acceptance and contract formation, the principle will be revolted and offeror has no right for withdrawal, unless in cases with contractual or legal reason. In addition, the contract follows a law in which the conclusion time is binding and in case of changed legislation, the governing law is specified by contract conclusion time determination.

It is also important to determine contract formation place. In accordance with Article 13 of the Code of Civil Procedure in commercial disputes as well as in each case on movable property which is derived from the contract, the plaintiff can refer to the local court where the contract is placed there. The contract formation place determination is important also in Private International Law since due to Article 968 of the Civil Law, the commitments derived from contracts follow contract occurrence place.

In normal contracts where parties to the transaction are present, time and place of the contract conclusion are clear and there is no unambiguous; but regarding the correspondence contracts, this issue is addressed and has resulted in diverse votes.

Regarding contract formation time, four theories have been presented: volition declaration theory, sending theory, receipt theory and information theory. As per many scholars' explanation, two former theories are very similar and occasionally are called as issuance theory while the two latter ones have plenty of similarities and actually it can be argued that there are two fundamental theories: acceptance issuance theory and awareness of acceptance theory. The well-known theory in Iranian law regarding the remote contracting is the sending theory because since sending acceptance, the content change is out of individual authority and what he has sent is his absolute volition. According to article 339 of the Civil Code, upon the seller and the customer's agreement in sales and prices, the contract of sale is offered and accepted..., and with the explanation that Iranian legislator never knows offeror's knowledge of the acceptance or receipt of acceptance as the contract condition, some scholars conclude that the acceptance issuance theory can be accepted in Iranian laws and recognize its sending as acceptance; unless, it is proved that acceptance has occurred at a time prior to sending. Issuance and acceptance declaration theory is adopted in the regulations of Kuwait, Lebanon, Syria and Jordan, as well. For example, article 184 of the causes and contract laws of Lebanon states that if the transactions or bargaining cases are done through correspondence or the presence of an interface between two absent parties, then the contract conclusion will be considered in the time and place in which agreement is gained at the time and place by someone receiving the contract. And article 98 of Syrian civil law states that the contract between two absent parties in the agreed time and place will be valid until the agreement or script requiring cases other than the contract may not be found (Roshdi, 1998).

\subsection{The Time and Place at Electronic Contracts in UNCITRAL Model Law and Iranian E-Commerce Law}

Since parties' offer and acceptance are almost done in a place and a time, it is not difficult to determine the time and place of contract formation in normal and traditional contracting where the parties form the contract in their presence, offer and acceptance are done in a very short time. But since a time gap is made between offer and acceptance- which form the contract- in absents contracts (remote contracting), time and place of contract is somewhat difficult to be determined.

The contracts concluded in e-commerce area are considered as absents contract type and therefore one of the legal issues addressed in electronic transactions is contract formation time and place determination. However, it is noteworthy to mention that, these forms are not special for e-commerce, but since international trade has been 
thriving and transactions have been flourished among diverse nations and also by using communication means such as phone, telefax and telegram in business, this issue has been paid into attention by legal systems and lawyers due to its importance and plenty of legal correspondences it brings up.

Nature of contract is confined to time and place aspects like emergence of anything else. Therefore, contract formation time and location is of the main contractual specifications whose determination leads to several legal results (Nouri, 2001).

\section{Conclusion}

Electronic contracting is one of the most important legal issues of e-commerce. Information technology has allowed lots of business transactions and service delivery to be done through internet. Expansion of this kind of trade and commercial relations among individuals has been along with addressing some legal issues on rules governing on people's contractual relations. These are some important topics in this area: recognition of modern communication technologies in contract formation, the way of their formation and credibility, the ability to assign electronic documents, issues related to electronic signatures, the way of electronic payments, etc.

Electronic contracts mean any agreement concluded by electronic interfaces. In other words, declaration of written volition in electronic format includes the cooperation and agreement of two or more parties to establish legal effects through electronic means. As a result, electronic contracts are not a specific type of contracts and for this reason, their sentences are considered under the general rules of contracts. Therefore, due to the special status of electronic transactions, some specifications of these contracts require legal assessments and analyses or matching with general rules of contracts. From studying electronic contracts, the following results are obtained:

1) Electronic contracts are of the contracts between absents and event it can be argued that such a title has more suitability than correspondence contracts because in electronic contracts- unlike correspondence ones- the parties do not know each other and may not have seen other. Although nothing is pointed in Iranian civil law about contract between absents, this kind of contract is accurate and valid.

2) Declaration of volition through electronic interfaces is valid and is effective to provide legal natures since the Iranian Civil Law has stated nothing on how to declare volition. Article 191 of Civil Law has absolutely declared companionship of intention with what implies on it as effectiveness condition of intention and has not mentioned intention or special means for implication of intention. Therefore, offer and acceptance can be declared through data messages and have necessary legal validity. In better words, digital or virtual nature of the parties' agreement is accurate in legal analysis and has no legal restrictions.

3) Although electronic contracts are completely concluded in a virtual and intangible environment, the legal nature cannot be separated from time and place. As a result, these contracts are confined to time and location. The Iranian Electronic Commerce Act has predicted special rules on time and place of data messages sending and reception and according to mentioned rules, electronic contract formation time is the reception time of the data messages containing acceptance.

4) The data message-based electronic contract documents are as valid as paper documents. According to Article 6 of Iranian Electronic Commerce Acts, when the presence of a writing is legally accurate, data message is considered as a writing. Therefore, electronic documents can be argued as valid as paper ones in the trials. The Electronic Commerce Act has no clear answer on whether data messages are normal documents or formal ones. However, since Article 14 of this Act has used valid and arguable documents, it can be stated that legislator mostly tends to formal documents.

5) The electronic documents to be valid should hold signature, like paper ones. If electronic signature is attached to data messages (considering safety and technical conditions), then electronic documents will legally be as valid as written documents.

6) Electronic signature on Iranian Electronic Commerce Act has been predicted as one of the actions with similar legal effects to manual signature. According to mentioned Article, electronic signature suffices whenever signature presence is necessary. By providing reliable technical infrastructures which are considered by Act for electronic signature, electronic signature can be argued to have no legal difference with manual ones.

The mentioned issues are addressed due to special specifications of electronic contracts conclusion environment and even in many cases, no new legislation is required, but by analysis and assessment of existing rules, the appropriate response can be found for addressed challenges of contract law in cyberspace and also as possible new legislation can be prevented. What mentioned does not mean that the new environment of electronic 
transactions do not need new legislation. It should be accepted that internet (as the location of individuals' legal relations) has some specifications which were absent in the technologies prior to internet emergence. For this reason, the made revolutions and changes in individuals' legal and transaction relations are paid into attention by legal systems and most of them have applied for providing a legal framework and legislative structuring in order to enact a new law or modify existing laws.

The rules governing electronic contracts have not generated new concepts which require enacting specific and special principles and it can be argued that Information Technology has revolutionized legal instances not legal concepts. Therefore, the rules governing electronic contracts are actually a reflection of general rules of the contracts whose conditions are matched with cyberspace. The rules enacted regarding e-commerce (including Iranian Electronic Commerce Acts) do not aim to establish new and specific legal principles, but these rules actually mean recognition of modern electronic tools in legal and business relationships and seem to be enacted to attract public trust and regulate individual relationships.

\section{Technological Restrictions of Electronic Commerce}

1) There is no widely accepted standard for quality, security and validity.

2) The seller is unknown in Electronic Commerce.

3) Software tools are not acceptable.

4) E-commerce profit cannot be easily measured.

5) There are still some problems to match internet and e-commerce software packages with some applications and databases.

6) Some customers would like to touch purchases product and do not adapt themselves with e-commerce.

7) The people do not still believe in paperless transactions.

8) In addition to network servers, some web servers are also required.

\section{Suggestions and Solutions for E-Commerce Development in Iran}

1) Determining the information needs from each class and presenting online information by the corresponding organization

2) Supporting governmental organizations to share commercial information

3) Activating commercial advisory centers in foreign countries to get more information on business areas of those countries

4) Studying and changing business laws for simplicity in use of EC

5) Training culture of using EC for firms and companies

6) Modification and enhancement of the telecommunications infrastructures and making high-speed and broadband telecommunications lines

7) Making security in the use of computer networks through prevention of legal intervention

8) More collaboration of the organizations associated with the business (Central Bank, Commercial Ministry and Customs) for suitable implementation of EC.

9) Studying and revolutionizing Iranian banking system for simplicity in use of EC

10) Studying the required changes in the legal regulations and rules associated with $\mathrm{EC}$

\section{References}

Abu Al Hasan Mujahid, O. (2000). khosusia al ta ’aqud abr al enternet, dar alnihza, Cairo.

Ahmadi, H., \& Virginiari, M. (2000). Electronic Commerce. Training and Industrial Research of Iran.

Alipour Hafezi, M. (2001). E-commerce in information centers. Speech. World Congress on electronic and Internet cities. Kish Island. 1st to 3rd of May.

Bagheri, P., \& Hassan, K. H. (2012). Electronic commerce and consumer protection in iran: A legal framework. International Business Management, 6(3), 37-324. https://doi.org/10.3923/ibm.2012.317.324

Feize Chekab, G. (2004). Contract conclusion moment through electronic interfaces. Proceedings of Conference on legal aspects of Information Technology, Salsabil Publications.

Ghasemzadeh, S. M. (2006). Civil Law, Contracts Basics and Commitments (2nd ed.). Dadgostar Publications. 
Tehran.

Ghezel Ayagh, M. (2001). Internet based e-commerce. Global conference on electronic and internet cities.

Habibzadeh, T. (2011). Tadlis Formation in electronic contracts. Justice Legal Journal, 74(71), 111-123.

Hasani. (2007). Requirements and needs for e-commerce in Iran, Iranian industry innovators website.

Mamduh Ibrahim, K. (2005). ibram al aqd al electrony, dar al fikr, Cairo.

Mirabi, V. R., \& Sarvsaeidi, S. (2003). Marketing management in the third millennium, derived from the book "Electronic Commerce".

Nikbakhs Tehrani, M. H., \& Azarsaberi, M. (2001). Awareness with e-commerce and its infrastructures. ISIRAN institution.

Nouri, M. (2001). Legal Notes (1st ed.). Tehran: Ghoghnous.

Rashidi. (2011). Electronic or Traditional Commerce?

Roshdi, M. A. (1998). Al-taqaud bevasaet al-itisal alhadisa ma `a al-takiz a 'al al-bie bevaseta al-telfezion (1st ed.). Kuwait, Kuwait University.

Safaei, S. H. (2007). Civil Rights Foundations (Vol. 2, 5th ed.). Tehran.

Sanayei, A. (2002). E-commerce in third millennium. SID Publication, Isfahan Branch.

Shahidi, M. (1998). Contracts formation and commitments. Hoghoughdan Publishing, Tehran.

Vesali Naseh, M. (2007). The paper of electronic contract and its validity foundations.

Zargar, M. (2001). Strategic models and business solutions in internet. Behine Publications.

\section{Copyrights}

Copyright for this article is retained by the author(s), with first publication rights granted to the journal.

This is an open-access article distributed under the terms and conditions of the Creative Commons Attribution license (http://creativecommons.org/licenses/by/4.0/). 